\title{
Drivers of herb-layer species diversity in two unmanaged temperate forests in northern Spain
}

\author{
F. M. Sabatini1 1,3,*, B. Jiménez-Alfaro², S. Burrascano ${ }^{1}$ and C. Blasi ${ }^{1}$ \\ ${ }^{1}$ Department of Environmental Biology, University of Rome, Rome, Italy \\ 2 Department of Botany and Zoology, Masaryk University, Brno, Czech Republic \\ ${ }^{3}$ Corresponding author. Tel.: 00390649912845; Fax:00390649912420; E-mail: francescomaria.sabatini@uniromal.it
}

Keywords: Beta-diversity, European beech, Multiple Regression on Distance Matrices, Old-growth, Sessile oak.

Abstract: The identification of the drivers of diversity in understorey plant assemblages is a major challenge in forest ecology. However, it is not yet fully understood whether the same factors consistently affect different facets of species organization, such as species richness, composition and turnover. Here, we compare the influence of fine-scale environmental variables and spatial organization on the herb-layer flora of two unmanaged and ecologically different forest stands in the Muniellos Biosphere Reserve, Northern Spain. The aims of our study are to identify the most important factors influencing different facets of herb-layer plant organization, and to test whether the effect of such drivers is consistent across facets and forest types. We used Generalized Linear Models, Redundancy Analysis and Multiple Regression on Distance Matrices to model, respectively, the response of species richness, species composition and species turnover to spatial distances as well as to several environmental factors, including forest structure, light conditions, soil and topographical features. We observed a substantial consistency among variables affecting the different facets of ground-layer species organization within stands, with a subset of topographical variables with a transversal effect across facets. Although potential solar radiation was the main variable influencing species richness in the two stands, the factors shaping species composition and turnover varied across forest types: in the beech stand, slope and canopy openness were the main determinants of herb-layer species diversity and turnover; in the oak stand, the main drivers of species composition were related to topography and spatial structure, while spatial distance was the main driver of species turnover. Our study shows that the ecological processes driving fine-scale variation of ground-layer plant richness and composition are similar to those driving species turnover. Although the ecological factors shaping different facets may be the same, we highlight that, at least in temperate forests, these factors are system-specific and vary according to forest types.

Abbreviations: GLM - Generalized Linear Models, MRM - Multiple Regression on Distance Matrices, PAR - Photosynthetic Active Radiation, PCNM - Principal Coordinates of Neighbour Matrices, PCO - Principal Coordinates Analysis, RDA Redundancy Analysis, VWC - Volumetric Water Content

Nomenclature: Euro+Med (2006-) Euro+Med PlantBase - the information resource for Euro-Mediterranean plant diversity. http://ww2.bgbm.org/EuroPlusMed/

\section{Introduction}

Ground-layer plant communities host the vast majority of forest biodiversity and provide habitat and forage for many wildlife species (Gilliam 2007). Furthermore, the herb-layer plays an important role in the functioning of forest ecosystems, influencing nutrient fluxes (Larsen 1995) and successional pathways (Royo and Carson 2006). The identification of those underlying mechanisms that affect the spatial distribution of ground-layer species is crucial for understanding the effect of anthropogenic disturbance on forest biodiversity and functioning, and for implementing management and conservation strategies for forest ecosystems.

In temperate and boreal forests, ground-layer vegetation is strongly influenced by overstorey composition and structure, since overstorey competes strongly for light and water (Barbier et al. 2008, Burrascano et al. 2011). Other key drivers are topographical and edaphic factors (Burton et al.
2011), as well as spatial-dependent endogenous (e.g., species dispersal-limitation) or stochastic processes (Hubbell 2001, Tuomisto et al. 2003). When assessing the relative importance of these drivers in European forests, one should always bear in mind that these systems have undergone large-scale and long-term anthropogenic disturbance due to land use and timber harvesting (Barbati et al. 2012).

Historical contingencies, such as land-use history and forest management, may have weakened the relationships between species distribution (and abundances) and environmental gradients. Ground-layer species often respond to disturbance with a temporal lag, and their distribution may depend on environmental conditions that no longer occur in a forest stand. For this reason unmanaged forests, i.e., forests where the signs of former human impacts have faded after decades without forestry operations, provide an excellent opportunity to study the influence of environmental drivers on ground-layer communities. Unmanaged forests are, indeed, 
often used as a reference model for understanding natural development processes, through the observation of the temporal and spatial interactions between successional processes, disturbance events, and tree mortality (Mikac et al. 2013). The study of these forests is usually considered as a means for evaluating human impacts on forest ecosystems, as well as for improving current sustainable management practices that emulate natural ecological processes and disturbance regimes (Travaglini et al. 2012, Burrascano et al. 2013b, Višnjić et al. 2013).

A thorough understanding of the environmental drivers shaping ground-layer plant communities may also be hampered by the fact that the relative importance of each ecological factor is likely to differ when one considers different facets of plant organization. A primary aspect of community diversity is species richness (i.e., the number of species observed in plots as a measure of alpha-diversity). Other relevant components of diversity are species composition (i.e., the relative abundance of different species) and beta-diversity (defined by Whittaker (1960) as 'the extent of change in community composition, or degree of community differentiation, in relation to a complex-gradient of environment, or a pattern of environments').

Ground-layer species richness has often been related to the availability of key resources, such as light, soil nutrients and water (Pausas et al. 2001, Bartels and Chen 2010). When these resources represent limiting factors, they may act as an environmental filter that influences both species richness and composition (Sabatini et al. 2014a). Other important drivers of species richness and composition are biotic interactions (e.g., competition) and historical processes, such as colonization and local extinctions (Pausas et al. 2001), whose effect is often mediated by changes in beta-diversity (Hubbell 2001, Tuomisto et al. 2003, Jones et al. 2006). Beta-diversity depends more on the degree of heterogeneity in resource availability than on their availability alone (Tuomisto et al. 2003, Bartels and Chen 2010), since a fine scale partitioning of resources may create high niche diversity and hence allow a higher compositional variability between sampling plots (Pausas et al. 2001, Ricotta et al. 2010). Species richness, composition and beta-diversity patterns are thus simultaneously influenced by biological interactions, random variation, dispersal limitation and environmental determinism through different mechanisms (Tuomisto et al. 2003, Burrascano et al. 2013a, Li et al. 2011).

These three facets of diversity are thus somehow related to each other (Tuomisto 2010a,b, Zhang et al. 2010), as has also been shown in simulation studies (Goslee 2010). However, few real-data studies have simultaneously compared different facets of species organization with environmental drivers, since researchers usually focus on one facet at the time (but see Li et al. 2011). Here, we compare the influence of fine-scale environmental variables and spatial distances on ground-layer plant organization in two forest types of the Muniellos UNESCO-MAB Biosphere Reserve (northern Spain). This reserve hosts one of the largest and best preserved sessile oak-dominated forests in Western Europe (Blanco Castro et al. 1997). We selected two stands represent- ing the two extremes of the ecological and compositional gradient existing in the reserve, a xeric forest stand dominated by sessile oak (Quercus petraea) and a mesic European beech (Fagus sylvatica) stand. The aim of our study is to determine the main drivers affecting ground-layer richness, composition and turnover, and to compare their relative importance across facets. We also tested whether the environmental drivers of these facets are system-specific or consistent across the two forest types.

We hypothesized that (i) the most limiting environmental factor, or factors, in each stand plays a primary role on all three facets of species organization. In particular, we predicted that variables related to xericity are critical in the sessile oak stand, since it develops on a steep, southern aspect slope (Fernández Prieto and Bueno Sánchez 1992). Similarly we predicted that variables related to light availability are determinant in the beech stand, since the canopy of beech forests is known to severely limit the development of the herb layer (Barbier et al. 2008, Burrascano et al. 2011). Furthermore, we hypothesized that (ii) the relative importance of different environmental and structural variables depends on their degree of fine-scale ecological heterogeneity (Jones et al. 2006). Besides the effect of environmental and structural variables, we expected (iii) to observe a significant effect of spatiallyexplicit endogenous processes (e.g., dispersal) on beta-diversity, since at local scales floristic patterns are expected to be strongly influenced by dispersal limitation (Guèze et al. 2013).

\section{Methods}

\subsection{Study area}

The Muniellos Biosphere Reserve is a protected and restricted access area of 55,657 ha that encompasses a core area of 8,661 ha. The reserve is located in the Cantabrian range, Asturias, NW Spain (Figure 1), in a region characterized by a warm and moist-temperate climate that is included in the Atlantic biogeographic region of Europe (Roekaerts 2002). Winters are cold with frequent snowfalls and frosts from December to February. Mean annual temperature is $10{ }^{\circ} \mathrm{C}$ and mean annual precipitation is $1459 \mathrm{~mm}$ (data from the reserve meteorological station, $650 \mathrm{~m}$ a.s.1.). About $80 \%$ of the Muniellos Reserve is covered by forest (Fernández Prieto and Bueno Sánchez 1992), spanning an altitudinal range from 600 to 1800 meters a.s.1. This forest was partially managed from 1766 onwards, and was withdrawn from silvicultural activities in 1973, when the natural reserve was established (López Alvarez 2002). Since the exploitation was never intense, many Muniellos stands display old-growth attributes, such as uneven-aged structure, the occurrence of very large trees, and the abundance of deadwood.

The forest in Muniellos is mainly dominated by sessile oak and is classified in two well-defined types (Fernández Prieto and Bueno Sánchez 1992). Xeric forests, which are characterized by Linaria triornitophora and Erica arborea, are mainly found on southern slopes, with the peculiar oc- 


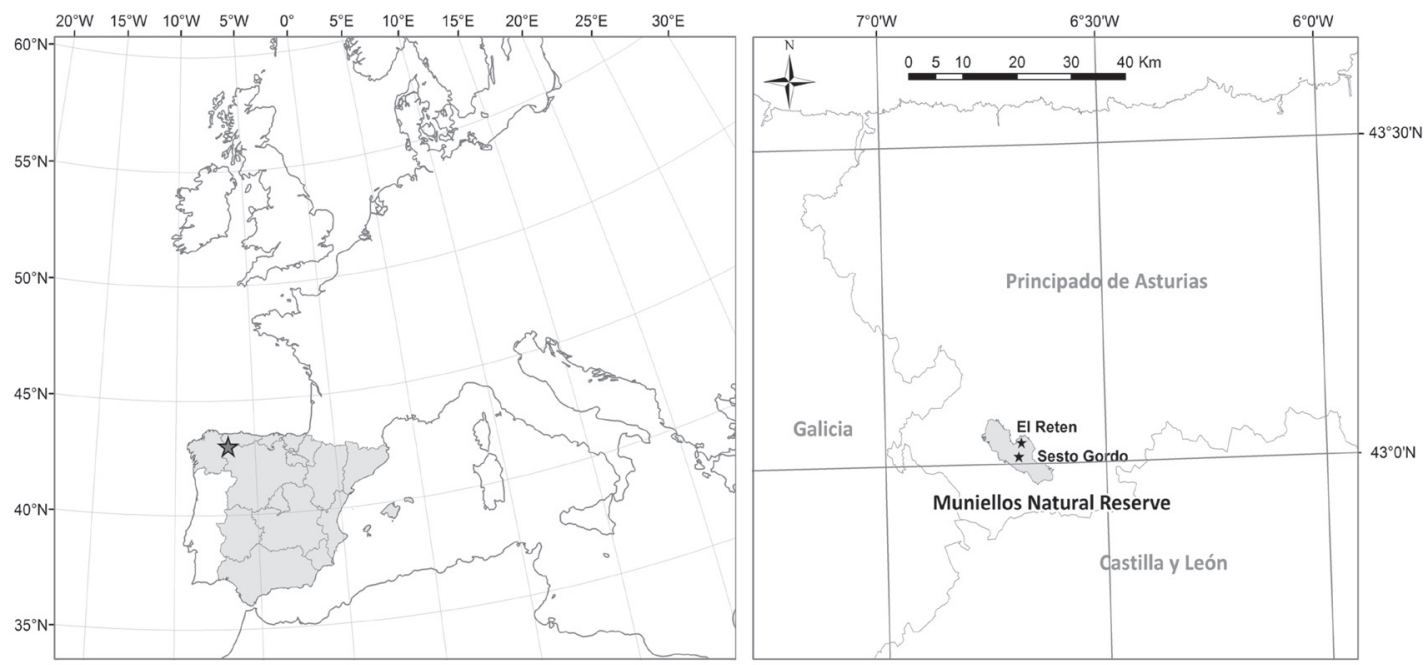

Figure 1. Study area. Location of Muniellos UNESCO-MAB Biosphere Reserve and of the two 1-ha macroplots. Beech forest (site: 'Sesto Gordo') and sessile oak forest (site: 'El Reten').

currence of the regional endemic orocantabrian oak (Quercus orocantabrica) near the timberline and Quercus pyrenaica in a few dry valleys. Mesic forests are dominant on northern slopes and are dominated by European beech and Iberian white birch (Betula pubescens var. pubescens, in northern Spain referred to as Betula celtiberica), which are predominant, respectively, in narrow valleys and at high elevations. These forests are characterized by Luzula sylvatica and Polystichum setiferum.

\subsection{Sampling design}

On the basis of the vegetation map of Muniellos (scale 1:25,000, Fernández Prieto et al. 2002), aerial photography ('Plan Nacional de Ortofotografía Aérea de España', nominal scale $1: 50,000,2011$ ), and field surveys we selected two undisturbed stands at the end-points of a moisture gradient. The two stands are dominated respectively by sessile oak (xeric forest, locality 'El Reten', Lat. $43^{\circ} 1$ ' $56^{\prime}$ ' N, Long. $6^{\circ} 41$ ' $15^{\prime} \mathrm{W}$; 850-900 m a.s.1.) and European beech (mesic forest, locality 'Sesto Gordo', Lat. $43^{\circ} 0$ ' 37' N, Long. 6 42 ' 0" W; $1250-1300 \mathrm{~m}$ a.s.1.) and are located about $2.6 \mathrm{~km}$ apart, respectively, on the south-facing and north-facing slopes of the main Muniellos river valley (Fig. 1). In each forest type, a grid of 25 sampling quadrats was regularly arranged in a 1-ha macroplot. Quadrats were $5 \mathrm{~m} \times 5 \mathrm{~m}$ and were located at the centres of a $20 \mathrm{~m} \times 20 \mathrm{~m}$ regular grid. For each quadrat we sampled vegetation, forest structure and environmental variables.

Vegetation was sampled by layers: tree- (height $>3 \mathrm{~m}$ ), shrub- $(1.3<$ height $\leq 3 \mathrm{~m})$ and herb-layer (height $\leq 1.3 \mathrm{~m})$. The cover value of each species in each layer was assigned through visual estimation using an ordinal cover scale: $0.5,1$, $2,5,10,15,20$, and every 10 up to $100 \%$. Tree- and shrublayer total cover was visually estimated using the same scale. We recorded the diameter at breast height (dbh) of all the trees with a dbh $>2.5 \mathrm{~cm}$ occurring inside each quadrat. Quadrat basal area was calculated as the sum of the cross-sectional area of living stems. Since the effect of the overstorey may be exerted well beyond the $5 \mathrm{~m} \times 5 \mathrm{~m}$ quadrat, we also calculated the basal area (of both living and dead trees) on the basis of a variable radius plot centred on each quadrat. The variable radius plot was defined in the field through the use of a wedge prism that discriminates between trees that are to be sampled and those that are not on the basis of a trade-off between their distance from the centre of the plot and their size. The underlying criterion is the fact that smaller trees should be sampled in a smaller area, while the larger ones (being rarer) should be sampled in a larger area. Hereafter, we refer to this measure of basal area as 'prism basal area'.

Canopy openness was estimated by means of a hemispherical (convex) densiometer (Lemmon 1957); we averaged four readings taken from the centre of the quadrat towards the cardinal directions. In addition, for each quadrat we recorded: GPS metric coordinates, slope, aspect, percentage of exposed rocks and stones, and litter cover and depth. Data on slope and aspect were used to calculate above-canopy potential annual direct incident solar radiation $\left(\mathrm{MJ} / \mathrm{cm}^{2} \cdot \mathrm{yr}\right.$, McCune and Keon 2002).

We averaged five measurements of Volumetric Water Content (VWC, i.e., the ratio of water volume to soil volume) per quadrat using a soil moisture meter Field Scout TDR 100; readings were subjectively located to encompass all the variability of the quadrat. For each stand, VWC measurements were taken during the same day, at least 72 hours after the last rain. Diffuse light transmittance, i.e., the photosynthetically active radiation (hereafter 'PAR') reaching the ground layer, was sampled in each quadrat using a Licor Line Quantum Sensor - Li-191. Light measurements were collected at $1 \mathrm{~m}$ height on June 27 (beech stand) and 29 (oak stand) 2012 between 11.45 and 12.30 under sunny and partially cloudy conditions, respectively. Two measurements were taken within each quadrat, $1.5 \mathrm{~m}$ north and $1.5 \mathrm{~m}$ south of the quadrat centre, and their average was used in the analysis. 


\subsection{True species diversity}

The term 'beta diversity' has often been used as an 'umbrella' concept to refer to rather different kinds of heterogeneity, differentiation, rate of change or complementarity (Tuomisto 2010a,b). In this paper, 'true beta diversity' is used to refer to the specific quantitative meaning of the term, while 'species turnover' is used to refer to the proportion of species composition that changes among sampling units (Tuomisto 2010a,b).

We calculated true species diversity (Tuomisto 2010b) as:

$$
{ }^{q} D=\frac{1}{\sqrt[q-1]{\sum_{i=1}^{s} p_{i} p_{i}^{q-1}}}
$$

where $p_{i}$ is the proportional abundance of species $i, S$ is the total number of species, and $q$ is the order of the diversity. The denominator of equation (1) corresponds to the generalized mean of the proportional species abundances, weighted by the species abundances. The inverse of this mean is true species diversity that quantifies the effective number of species, i.e., the number of equally-abundant species that would give the same mean proportional species abundance as that observed in the dataset of interest.

True diversity was calculated both for $q=0$ and for $q=$ 2 ; when $q=0$, all species are treated as if they were equally abundant, and hence ${ }^{0} D$ has the same numeric value as species richness. When $q>1$, equation (1) gives more weight to abundant species, and when $q=2$ the denominator of (1) equals the original Simpson diversity index (Jost 2006). We used cover estimations to derive species abundance data.

Species diversity can be ascribed to two independent factors, i.e., average species density within sampling units and compositional heterogeneity between sampling units. To quantify the relative roles of these, we performed a multiplicative partitioning of the total observed species diversity in each stand (gamma diversity) following Tuomisto (2010b): $\mathrm{q} D_{\gamma}=\mathrm{q} D_{\alpha} \times \mathrm{q} D_{\beta}$. An ad hoc R-script to perform this calculation can be found in Sabatini et al. (2014b).

\subsection{Data analysis}

We produced a boxplot for each of the twelve explanatory environmental and structural variables in the two forest types, and tested whether the medians and variances of each environmental and structural variable differed between stands using non-parametric tests, i.e., Mann-Whitney-Wilcox test and Brown-Forsythe test, respectively. For PAR and VWC we only compared the variances; since these are transient variables and they were not sampled simultaneously in the two stands, the comparison of their medians is meaningless. Significance levels were adjusted for multiple comparisons using Holm's correction. Finally, we performed a non-parametric correlation analysis (Spearman's $\rho$ ) to check for multicollinearity among the structural and environmental variables for each forest type. Unless otherwise specified, analyses were performed using R version 2.12.0 (R Foundation for Statistical Computing, Vienna, Austria).

To test the influence of the environmental and structural variables on quadrat species richness we fitted, for each forest type, a Generalized Linear Model (GLM) assuming Poissondistributed errors and a log link function. The species richness per quadrat ( $N=25$ quadrats) was the response variable. For each stand, we first computed a separate model for each of the twelve environmental and structural explanatory variables, to select those with a significant effect on species richness. Those variables with a significant marginal effect (i.e., the effect of an individual variable ignoring the others) were introduced into a multi-variable GLM. Parsimonious best-fitting models were then selected using a stepwise variable selection using the second-order Akaike Information Criterion (AICc), which corrects for small sample sizes. The significance of predictors was then calculated by means of a deviance test using the $X^{2}$ criteria: only those predictors with a significant $(p<0.05)$ increase in residual deviance were retained. In order to assess the potential influence of spatial autocorrelation, we computed Moran's I over the model residuals for the two stands.

To analyse species composition and turnover, we followed the methodological framework proposed by Tuomisto and Ruokolainen (2006). They identified various levels of abstraction at which ecological hypotheses on the distribution of species along spatial and environmental gradients can be formulated and tested. In particular, they highlighted differences and complementarity between (i) raw-data approaches (direct ordination such as RDA or CCA), suitable for ecological questions focused on the variation in species composition (Chavez and Macdonald 2010, Yu and Sun 2013), and (ii) distance-based approaches (Mantel test or Multiple Regression on Distance Matrices) whose application should be limited to ecological questions focused on beta-diversity variation ( $\mathrm{Li}$ et al. 2011, Guèze et al. 2013, Burrascano et al. 2013a).

According to this framework, we used redundancy analysis (RDA) in CANOCO 5 (Biometrics, Wageningen, The Netherlands) to test the null hypothesis that species composition is independent of explanatory variables in the two forest stands. Species cover data were first converted to logarithm and then Hellinger transformed. In addition, spatial structure was modelled using Principal Coordinates of Neighbour Matrices (PCNMs), a method that achieves a spectral decomposition of the spatial relationships between the sample sites, returning the scales at which a data table of interest responds (Borcard et al. 2004). The marginal effect and significance of each explanatory variable were first tested individually by fitting separate RDAs. Significant variables were then used to compute a forward selection procedure using two stopping criteria, (i) an alpha significance level of 0.05 , and (ii) the adjusted coefficient of multiple determination (Blanchet et al. 2008); finally, we estimated their conditional effect (i.e., the effect of a variable after accounting for the other explanatory variables). The null hypothesis of no effect of each variable on species composition was tested using 499 Monte Carlo permutations. In addition, we computed variance partitioning of the eigenvalues of RDA (Borcard et al. 1992) to test 
Table 1. Results of the GLM analysis assessing the influence of the environmental variables on species richness in two forest types sampled in the Muniellos Biosphere Reserve, northern Spain. We report Z- and p-values of each explanatory variable considered individually. We also report the percentage of explained deviance of those significant variables that were retained in the multi-variable model after forward selection (in bold). PAR - photosynthetic active radiation; VWC - volumetric water content.

\begin{tabular}{|c|c|c|c|c|c|c|}
\hline & \multicolumn{3}{|c|}{ Beech stand } & \multicolumn{3}{|c|}{ Oak stand } \\
\hline & Z-value & p-values & $\begin{array}{l}\text { Explained } \\
\text { Deviance }\end{array}$ & Z-value & p-values & $\begin{array}{l}\text { Explained } \\
\text { Deviance }\end{array}$ \\
\hline PAR & . & $n s$ & . & . & $n s$ & . \\
\hline Canopy openness & . & $n s$ & . & . & $n s$ & . \\
\hline Tree cover & . & $n s$ & . & . & $n s$ & . \\
\hline Slope & 3.541 & 0.000 & & . & $n s$ & . \\
\hline $\begin{array}{l}\text { Potential solar } \\
\text { radiation }\end{array}$ & -3.514 & 0.000 & $33 \%$ & -4.574 & 0.000 & $40 \%$ \\
\hline VWC & . & $n s$ & . & . & $n s$ & . \\
\hline Exposed rocks & . & $n s$ & . & -2.099 & 0.036 & $7 \%$ \\
\hline Litter cover & . & $n s$ & . & . & $n s$ & . \\
\hline Litter depth & . & $n s$ & . & . & $n s$ & . \\
\hline Shrub cover & . & $n s$ & . & -3.512 & 0.000 & . \\
\hline Basal area (prism) & . & $n s$ & . & . & $n s$ & . \\
\hline Basal area (quadrat) & . & $n s$ & . & . & $n s$ & . \\
\hline
\end{tabular}

the partial contribution of the environmental variables and the spatial structure of the samples.

Finally, we used a Multiple Regression on Distance matrices (MRM, Lichstein 2007) to assess what explanatory variables drive the variation of ground-layer species turnover in each stand, as calculated by means of a pairwise quadratto-quadrat Hellinger dissimilarity matrix based on groundlayer species composition. As explanatory variables, we used quadrat-to-quadrat matrices of Euclidean dissimilarities calculated for each environmental and structural variable separately after standardization, as well as a matrix of spatial distances between pairs of quadrats. These matrices were used one at the time as explanatory variables in MRM models to estimate their marginal effect and significance in explaining species turnover. Significant variables were included in a second model to quantify the total variation explained, and to identify those variables with a significant conditional effect on the prediction of species turnover. MRM was calculated using the function 'MRM' in the 'ecodist' (version 1.2.5) R package.

\section{Results}

\subsection{Diversity and environmental conditions of the forest stands}

The canopy of the oak-dominated stand was relatively closed and homogeneous, and was composed of Quercus petraea alone. The shrub layer was locally dominated by dense clusters of Erica arborea, with scattered individuals of Genista florida subsp. polygaliphylla. A total of 40 species $\left({ }^{0} D_{\gamma}\right)$ occurred in the herb-layer; the average alpha diversity at $q=0\left({ }^{0} D_{\alpha}\right)$ was 7.7 with ${ }^{0} D_{\beta}=5.2$. The most common species were Ceratocapnos claviculata, Luzula lactea and Holcus mollis. The average herb-layer species diversity per quadrat was ${ }^{2} D_{\alpha}=2.3$, with ${ }^{2} D_{\beta}=4.2$ and ${ }^{2} D_{\gamma}=9.7$.

The canopy of the beech-dominated stand was more diverse than that of the oak stand; it was mainly composed of Fagus sylvatica and Betula pubescens, with scattered emergent individuals of Quercus petraea and sparse individuals of Ilex aquifolium $\mathrm{L}$. in the shrub layer. The herb-layer of quadrats with low canopy cover was dominated by Luzula sylvatica, co-occurring locally with Pteridium aquilinum. Other common species were Avenella flexuosa, Stellaria holostea and Vaccinium myrtillus, the last of these often growing on decaying logs. The herb-layer, which was less diverse than that of the oak stand, contained a total of 25 species $\left({ }^{0} D_{\gamma}\right)$; the average alpha diversity at $q=0\left({ }^{0} D_{\alpha}\right)$ was 5.2 with ${ }^{0} D_{\beta}=4.8$. Given the strong dominance of few clonal species, the herblayer species diversity at $q=2$ was low, with ${ }^{2} D_{\alpha}=1.5,{ }^{2} D_{\beta}=$ 1.2 and ${ }^{2} D_{\gamma}=1.8$.

The oak stand displayed higher average potential solar radiation (Mann-Whitney-Wilcox test $\mathrm{W}=625, \mathrm{p}<0.001$ ), slope $(\mathrm{W}=531, \mathrm{p}<0.001)$, exposed rocks $(\mathrm{W}=534, \mathrm{p}<$ $0.001)$, and shrub cover $(\mathrm{W}=625, \mathrm{p}<0.001)$ than the beech stand, which instead displayed a higher average litter depth $(\mathrm{W}=93, \mathrm{p}<0.001)$. The beech-dominated stand was characterized by higher environmental heterogeneity than the oakdominated stand: the variables with a significantly higher variance were PAR (Brown-Forsythe test, $\mathrm{F}=19.4, \mathrm{p}=0.001$ ), canopy openness $(\mathrm{F}=9.3, \mathrm{p}=0.032)$, litter depth $(\mathrm{F}=9.6$, $\mathrm{p}=0.027)$, and slope $(\mathrm{F}=16.3, \mathrm{p}=0.002)$. By contrast, the oak forest was characterized by higher heterogeneity of shrub cover $(\mathrm{F}=25, \mathrm{p}<0.001$, Fig. 2, Table $\mathrm{S} 1.1)$.

Correlation analysis (Table S2.1, Table S2.2) revealed significant collinearity between several explanatory variables. Variables that modelled light availability at ground layer, whether directly (i.e., PAR) or indirectly (i.e., tree lay- 

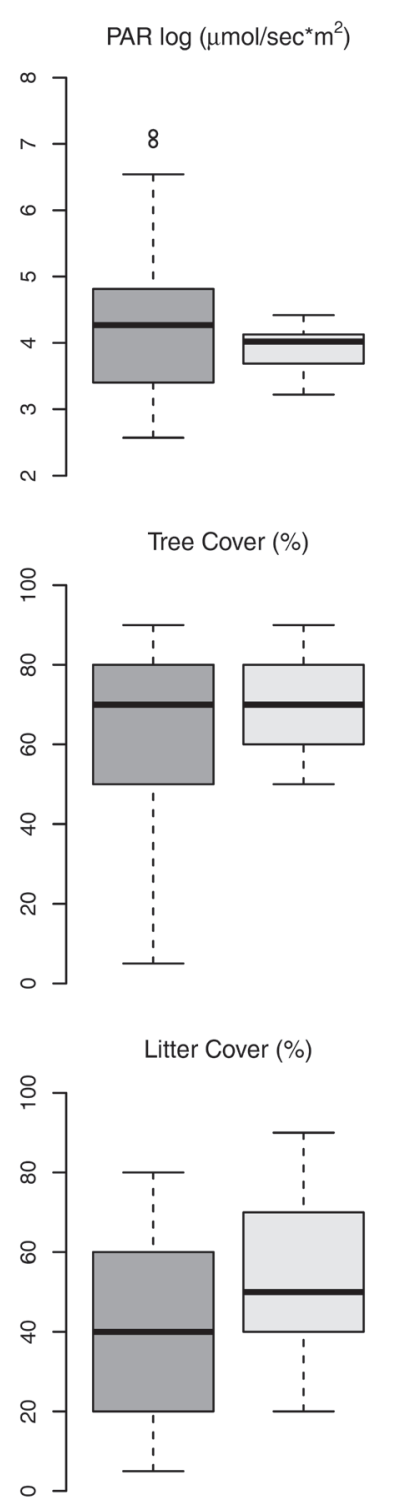

Litter Cover (\%)

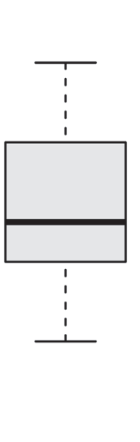

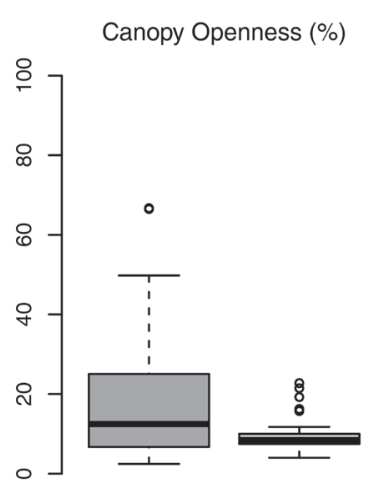
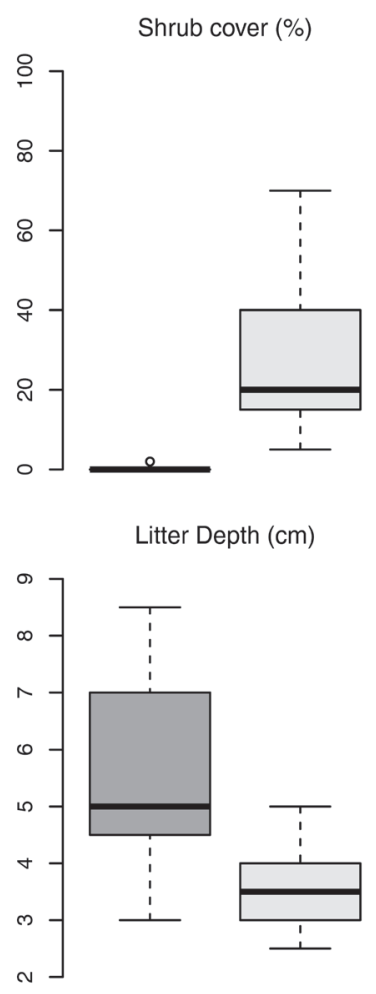
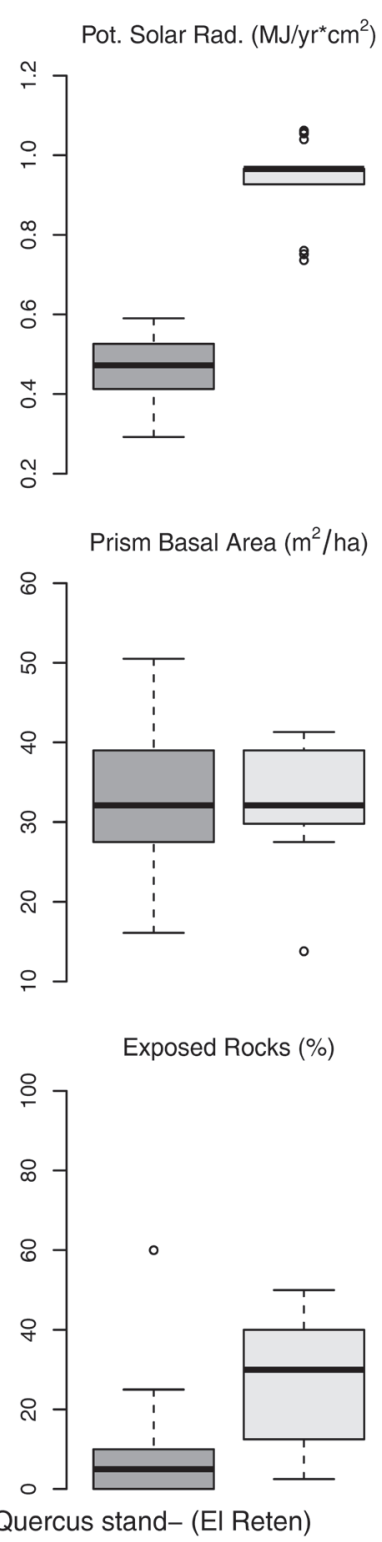

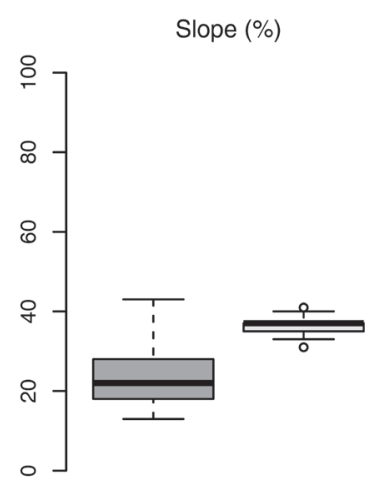

Quadrat Basal Area $\left(\mathrm{m}^{2} /\right.$ quad)

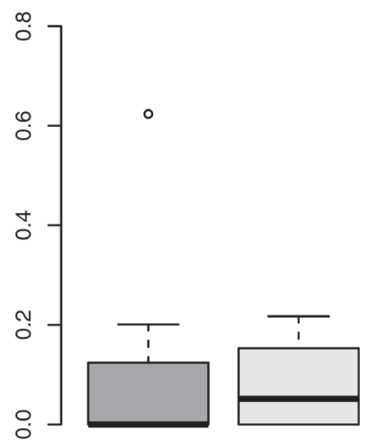

VWC (\%)

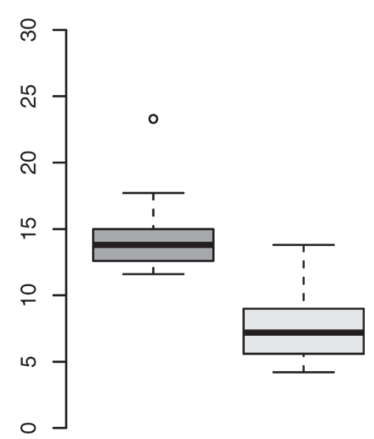

Figure 2. Boxplots of the distribution of environmental data collected in the 25 quadrats of the two 1-ha macroplots. The median, first and third quartiles, and whiskers (corresponding to 1.5 times the interquartile distance) are reported. Empty circles represent outliers.

er cover, canopy openness), were consistently correlated to each other and to other structural variables (e.g., quadrat, and prism basal area) in both stands. The highest correlation was observed in the beech-dominated stand between canopy openness and ground-layer PAR levels. In the beech stand (Table S2.1), basal area was correlated with both canopy openness (negatively) and tree cover (positively). Tree cover was also positively correlated with slope, which in turn was negatively associated with potential solar radiation. The correlations between explanatory variables were slightly different in the oak forest (Table S2.2). In this stand we observed high shrub cover values in quadrats with high potential solar radiation and high litter cover. Litter cover was also negatively related to the percentage of exposed rocks and to ground-layer PAR.

\subsection{Drivers of species richness}

Only a small subset of environmental variables were significantly related to ground-layer species richness, with important differences between the two forest types (Table 1, Fig. S3.1). In the oak-dominated stand, potential solar radiation $(\mathrm{AICc}=115.6)$ was negatively related to ground-layer species richness, as were exposed rocks $(\mathrm{AICc}=131.3)$ and shrub coverage $(\mathrm{AICc}=121.7)$. Potential solar radiation and exposed rocks had a significant conditional effect on species richness, accounting for $47 \%$ of the explained deviance. In the beech stand, the only two environmental variables with explanatory power on ground-layer species richness were slope (positively, AICc $=113.7$ ) and potential solar radiation (negatively, $\mathrm{AICc}=113.5$ ). Although both variables were 
selected in the stepwise selection, only potential solar radiation had a significant conditional effect on species richness, explaining $33 \%$ of the total deviance. Model residuals did not show spatial autocorrelation in either the oak (Moran's $I=0.15, \mathrm{p}=0.182$ ) or beech (Moran's $I=0.14, \mathrm{p}=0.208$ ) stands.

\subsection{Drivers of species composition}

The environmental variables that influenced ground-layer species composition differed between the two stands (Table 2 ). When environmental variables were considered separately, the ground-layer species composition of the oak stand was only influenced by potential solar radiation, exposed rocks and shrub cover. The first two variables were retained by forward selection in the multi-variable model. The ground-layer species composition of the beech stand was significantly related to light (canopy openness, tree cover, PAR), topography (slope, potential solar radiation), exposed rocks and prism basal area. The only significant variables retained after forward selection were slope, canopy openness and exposed rocks.

Variation partitioning displayed a significant effect of spatial structure in the oak stand though not in the beech stand. The final model in the oak stand explained $37.7 \%$ of variance. It included three environmental variables (tree cover, potential solar radiation and rockiness) and five spatial variables derived from PCNM coordinates. The amount of variation explained by environmental variables alone (a) was $3.6 \%$, by environmental and spatial variables combined (b) was $16.7 \%$, and by spatial variables alone (c) was $18 \%$. In the beech stand, the total explained variation was $46 \%$, and was accounted for only by environmental variables, since none of the PCNM spatial variables was significant.

\subsection{Drivers of species turnover}

Several variables had a significantly marginal effect on ground-layer species turnover in the beech forest (Table 3), i.e., tree layer cover, slope, potential solar radiation, exposed rocks and litter cover, as well as the spatial proximity of quadrats. The only variables that remained significant in the multi-variable MRM were tree cover and slope, which combined explained $47 \%$ of total variation. Conversely, in the oak stand, the only variables that yielded a significant result were potential solar radiation and spatial distance. However, only spatial distance had a significant conditional effect on the final model, and explained only $10 \%$ of total variation.

\section{Discussion}

\subsection{Consistency among drivers of species richness, composition and turnover}

We observed a substantial consistency among the variables influencing different facets of ground-layer species organization, i.e., species richness, composition and turnover. In particular, we found that those environmental factors that drive species composition are fairly similar to those that determine species turnover. The existence of a mathematical correspondence between the environmental factors affecting these two facets of species organization has been shown by using simulated data (Goslee 2010). However, this theoretical relationship holds true only under some strict assumptions that are seldom met in real data; for instance, a study investigating species organization in alpine meadows found that species composition and turnover were driven by different ecological factors ( $\mathrm{Li}$ et al. 2011). Despite being difficult to extrapolate to other habitats and geographical regions, our results show that both species composition and turnover may provide a similar understanding of the environmental factors driving species assemblages in temperate forests.

Overall, we found a strong topographical control on different facets of plant organization in two ecologically different forest stands. In both stands, potential solar radiation was the only variable found to have a significant conditional effect on species richness, as well as a significant marginal effect on species composition and turnover. Potential solar radiation is a compound variable derived from slope, aspect and latitude (McCune and Keon 2002) that serves, in the study system, as both a measure of potential energy input and a proxy of overall aridity related to topographical conditions. The negative effect of potential solar radiation on herb-layer species richness is also consistent with results reported for Korean temperate oak forests (Černý et al. 2013). The strong correlation between topographical variables, such as slope and potential solar radiation, and their importance in the study area is not surprising. Indeed, the Muniellos forest is characterized by a strong topographical gradient with very steep slopes on metamorphic rocks (schist) that probably affects soil features such as depth, texture, $\mathrm{pH}$, water retention capacity and nutrient availability. This gradient, in turn, exerts a strong physiological constraint on the structure and composition of plant assemblages (Fernández Prieto and Bueno Sánchez 1992).

\subsection{Differences between the underlying ecological gradients in the oak and beech stands}

Besides the transversal influence of topography, the ground-layer species assemblages in the two stands were not related to the same environmental variables, thus pointing to the occurrence of different underlying limiting factors. This result substantially supports our initial hypothesis according to which the fine-scale variation of ground-layer species richness, composition and turnover in each stand type is mainly affected by one, or a few dominant ecological gradients. These underlying gradients are the result of the complex interplay between several environmental variables (Table S2.1, Table S2.2) and biotic factors. Indeed, the overstorey composition and structure may represent a filter that modulates the distribution of resources within the forest and, in turn, the spatial patterning of the ground-layer (Burrascano et al. 2011, Burton et al. 2011, Sabatini et al. 2014ab).

The main gradient affecting ground-layer plant assemblages in the oak stand can be related to topography-induced xericity (demonstrated by the importance of potential solar 
Table 2. Relationships between species composition of two forest stands (Muniellos Biosphere Reserve, northern Spain) and 12 environmental variables. F- and p-values refer to the RDA models computed for each variable individually. We only report model output of those variables that have a significant marginal effect on species composition. Significant $(p<0.05)$ variables included in the final model after forward selection are in bold, and their corresponding variance explained (VE) is shown.

\begin{tabular}{|c|c|c|c|c|c|c|}
\hline & \multicolumn{3}{|c|}{ Beech stand } & \multicolumn{3}{|c|}{ Oak stand } \\
\hline & F-values & p-values & VE (full model) & F-values & p-values & VE (full model) \\
\hline PAR & 3.5 & 0.024 & . & . & $n s$ & . \\
\hline Canopy openness & 6.0 & 0.004 & $19.1 \%$ & . & $n s$ & . \\
\hline Tree cover & 5.7 & 0.010 & . & . & $n s$ & . \\
\hline Slope & 8.4 & 0.002 & $26.7 \%$ & . & $n s$ & . \\
\hline Potential solar radiation & 4.6 & 0.004 & . & 3.95 & 0.004 & $14.9 \%$ \\
\hline VWC & . & $n s$ & . & . & $n s$ & . \\
\hline Exposed rocks & 5.3 & 0.048 & $7.1 \%$ & 1.95 & 0.032 & $9.0 \%$ \\
\hline Litter cover & . & $n s$ & . & . & $n s$ & . \\
\hline Litter depth & . & $n s$ & . & . & $\mathrm{ns}$ & . \\
\hline Shrub cover & . & $n s$ & . & 2.12 & 0.040 & . \\
\hline Basal area (prism) & 3.6 & 0.008 & . & . & $n s$ & . \\
\hline Basal area (quadrat) & . & $n s$ & . & . & $n s$ & . \\
\hline
\end{tabular}

Table 3. Results of Multiple regression on Distance matrices assessing the influence of individual environmental variables on groundlayer species turnover in the two forest types (Muniellos Biosphere Reserve, northern Spain). We report regression coefficients, $\mathrm{R}^{2}$ and p-values only for those explanatory variables that have a significant marginal effect on species turnover. Variables with a significant $(\mathrm{p}<0.05)$ conditional effect in the final multiple regression model are in bold.

\begin{tabular}{|c|c|c|c|c|c|c|}
\hline & \multicolumn{3}{|c|}{ Beech stand } & \multicolumn{3}{|c|}{ Oak stand } \\
\hline & Coef & R2 & p-values & Coef & $\mathrm{R} 2$ & p-values \\
\hline PAR & . & . & $n s$ & . & . & $n s$ \\
\hline Canopy openness & , & . & $n s$ & . & . & $n s$ \\
\hline Tree cover & 0.135 & 0.147 & 0.015 & . & . & $n s$ \\
\hline Slope & 0.207 & 0.343 & 0.001 & . & . & $n s$ \\
\hline Potential solar radiation & 0.131 & 0.120 & 0.005 & 0.044 & 0.022 & 0.041 \\
\hline VWC & , & . & $n s$ & . & . & $n s$ \\
\hline Exposed rocks & 0.128 & 0.231 & 0.012 & . & . & $n s$ \\
\hline Litter cover & 0.069 & 0.034 & 0.025 & . & . & $n s$ \\
\hline Litter depth & , & . & $n s$ & . & . & $n s$ \\
\hline Shrub cover & , & . & $n s$ & . & . & $n s$ \\
\hline Basal area (prism) & , & . & $n s$ & . & . & $n s$ \\
\hline Basal area (quadrat) & , & . & $n s$ & . & . & $n s$ \\
\hline Spatial distances & 0.002 & 0.032 & 0.047 & 0.004 & 0.097 & 0.001 \\
\hline
\end{tabular}

radiation and exposed rocks) and to its interaction with shrub cover. Indeed, the quadrats located in the most xeric locations, with lowest soil humidity and highest percentages of exposed rocks, were mainly dominated by dense clusters of Erica arborea. These clusters were associated with a sparse, species-poor herb-layer characterized by species adapted to relatively xeric conditions that were found exclusively in this stand (e.g., Genista florida, Teucrium scorodonia). By contrast the environmental variables related to xericity were poor predictors of species turnover, for which MRM model returned a low amount of variation explained (Table 3, see par. 4.3).

In the beech stand, ground-layer compositional variability and species turnover (though not species richness) were related to light availability and were modulated by tree cover (or canopy openness) and by the negative effect of shade-tolerant tree species, such as beech, on understorey light levels and richness. This is consistent with our expectations as well as with evidence from the literature (Chiarucci et al. 2001, Ricotta et al. 2010, Burrascano et al. 2011). We also found a 
strong interaction between tree cover and slope, with consequent effects on almost every other environmental variable (Yu and Sun 2013). Indeed, the beech stand encompassed the upper part and the ridge top of a north-facing slope. Quadrats located on the ridge top were less steep and had a more open canopy than those located on the mountain slope, probably because trees located on the ridge top are more susceptible to wind damage. In ridge top quadrats, we observed a dense layer of Luzula sylvatica, locally associated with Pteridium aquilinum. By contrast, quadrats on the mountain slope experienced more mesic conditions, lower potential solar radiation and a denser canopy, which resulted in a sparse groundlayer vegetation mainly composed of forest interior species with very low light requirements, such as Oxalis acetosella and Blechnum spicant.

\subsection{The effect of fine-scale environmental heterogeneity and space}

Species composition and turnover were mainly determined by space in the oak stand and by environmental factors in the beech stand. This supports our prediction that species composition and turnover depend both on spatially-explicit processes and on those environmental variables that contributed most to the creation of within-stand ecological heterogeneity. The environmental factors that significantly explained species organization were often those with the longest gradient length, i.e., with the highest within-stand variability. For example, exposed rocks and shrub cover in the oak stand, and PAR, canopy openness, tree cover and slope in the beech stand, all displayed a relatively high degree of variability (Fig. 2) and were significant predictors of species composition and $\backslash$ or turnover (Table 2, Table 3). Indeed, when the sampled ecological gradient is long, the effect of an environmental variable may be easier to detect than when the gradient is truncated, as long as those gradients that exert an important direct influence on ground layer vegetation are considered (Jones et al. 2006, Guèze et al. 2013, Sabatini et al. 2014b).

The modest predictive capability of the MRM model in the oak stand may depend on the fact that the overall environmental conditions and structural characteristics of the oak stand are substantially more homogeneous than those of the beech stand. It is reasonable to assume that the higher the environmental heterogeneity is, the stronger the compositional differences of the ground-layer vegetation and the signal-to-noise ratio in the ecological analysis are (Gilbert and Lechowicz 2004, Tuomisto et al. 2003). Nevertheless, we found that the oak stand displayed both a higher species turnover (i.e., mean between-quadrat dissimilarity), and a true beta diversity more than three times higher than that of the beech forest. The high beta-diversity of the oak stand was not merely related to differences in species richness, but depended on a more even distribution of species abundances both within and among quadrats. These results suggest that stand environmental heterogeneity and beta diversity may not be directly related to each other but may be influenced by processes operating at different scales. Similar findings were reported in stands dominated by Turkey oak (Quercus cerris), which were compositionally more heterogeneous than beech stands at a fine scale, while the compositional variability of beech forests was found to be more marked at a broader scale (Chiarucci et al. 2001).

Spatial structure (reflected by PCNM in the RDA and spatial distances in the MRM) was an important predictor of species composition and turnover in the oak stand alone, suggesting that spatial-based processes (e.g., dispersal limitation) may have a greater importance in the oak than in the beech stand. The ground layer of the oak stand may be composed of a high proportion of low-dispersal or clonal species forming clusters of spatially aggregated species (Jiménez-Alfaro \& Iriondo in press), which results in a higher spatial autocorrelation of ground layer assemblages. This hypothesis deserves further testing, using for instance an approach based on the decomposition of ground layer assemblages into functional groups (e.g., low- vs. high-dispersal, shade tolerant vs. shade intolerant species, competitive vs. stress tolerant species).

The effect of spatial distances in the oak stand may also be related to important spatially structured environmental gradients we failed to measure, e.g., those directly related to soil xericity (e.g., soil depth, texture, organic matter content). We only measured two variables related to soil features: exposed rocks, which is considered a good proxy of soil depth (Burrascano et al. 2013a), and volumetric water content, which is related to soil texture and water retention capacity. However, only the former yielded significant results probably because VWC is a transient property that varies markedly according to the time lapse since the last precipitation, especially in highly draining soils such as those found in Muniellos. Another possible explanation may be found in past forest management. Since the oak stand is located in a more accessible area of the reserve than the beech stand, it was likely withdrawn from exploitation later than the beech stand. Although this effect is probably slight in our study system, the legacies of former anthropic disturbance might be more detectable in the oak than in the beech stand. The more recent cessation of disturbance in the oak stand may have resulted in a distribution of herb-layer species deriving from environmental conditions that no longer occur (Burton et al. 2011; Tobisch and Standovár 2005); after a change in the environmental conditions, long-lived species may survive for years in suboptimal conditions (Jiménez-Alfaro and Iriondo in press) and track new areas that become suitable with a temporal lag that may vary in length depending on species' dispersal abilities.

Acknowledgements: The original project was funded by grants (F.M. Sabatini) from Sapienza, University of Rome. We would like to thank E. Fernández-Pascual (Universidad de Oviedo, Spain) for his help during the field work, the Jardín Botánico Atlántico (Gijón, Spain) for its logistic support, and the regional government of Principado de Asturias for authorizing the field work in the Muniellos Biosphere Reserve. We would also like to thank L. Baker for revising the English of the text. F.M.S. and B.J.A. equally contributed to this paper. 


\section{References}

Barbati, A., R. Salvati, B. Ferrari, D. Di Santo, A. Quatrini, L. Portoghesi, D. Travaglini, F. Iovino and S. Nocentini. 2012. Assessing and promoting old-growthness of forest stands: Lessons from research in Italy. Plant Biosyst. 146:167-174.

Barbier, S., F. Gosselin, and P. Balandier. 2008. Influence of tree species on understory vegetation diversity and mechanisms involved - A critical review for temperate and boreal forests. For. Ecol. Manag. 254:1-15.

Bartels, S. F. and H. Y. H. Chen. 2010. Is understory plant species diversity driven by resource quantity or resource heterogeneity? Ecology 91:1931-1938.

Blanchet, F. G., P. Legendre and D. Borcard. 2008. Forward selection of explanatory variables. Ecology 89:2623-2632.

Blanco Castro, E., M. A. Casado González, M. Costa Tenorio, R. Escribano Bombín, M. García Antón, M. Génova Fuster, F. Gómez Manzaneque, J. C. Moreno Sáiz, C. Morla Juaristi, P. Regato Pajares and H. Sáiz Ollero. 1997. Los bosques ibéricos. Planeta, Barcelona, Spain.

Borcard, D., P. Legendre, C. Avois-Jacquet and H. Tuomisto. 2004. Dissecting the spatial structure of ecological data at multiple scales. Ecology 85:1826-1832.

Borcard, D., P. Legendre and P. Drapeau. 1992. Partialling out the spatial component of ecological variation. Ecology 73:10451055

Burrascano, S., F. M. Sabatini and C. Blasi. 2011. Testing indicators of sustainable forest management on understorey composition and diversity in southern Italy through variation partitioning. Plant Ecol. 212:829-841.

Burrascano, S., I. Anzellotti, E. Carli, E. Del Vico, L. Facioni, F. Pretto, F. M. Sabatini, A. Tilia and C. Blasi. 2013a. Drivers of beta-diversity variation in Bromus erectus semi-natural dry grasslands. Appl. Veg. Sci. 16:404-416.

Burrascano, S., W. S. Keeton, F. M. Sabatini and C. Blasi. 2013 b. Commonality and variability in the structural attributes of moist temperate old-growth forests: a global review. For. Ecol. Manag. 291:458-479.

Burton, J. I., D. J. Mladenoff, M. K. Clayton and J. A. Forrester. 2011. The roles of environmental filtering and colonization in the fine-scale spatial patterning of ground-layer plant communities in north temperate deciduous forests. J. Ecol. 99:764-776.

Černý, T., J. Doležal, Š. Janeček, M. Šrůtek, M. Valachovič, P. Petřík, J. Altman, M. Bartoš and J.-S. Song. 2013. Environmental correlates of plant diversity in Korean temperate forests. Acta Oecol. 47:37-45.

Chavez, V. and S. E. Macdonald. 2010. The influence of canopy patch mosaics on understory plant community composition in boreal mixedwood forest. For. Ecol. Manag. 259:1067-1075.

Chiarucci, A., V. De Dominicis and J. B. Wilson. 2001. Structure and floristic diversity in permanent monitoring plots in forest ecosystems of Tuscany. For. Ecol. Manag. 141:201-210.

Fernández Prieto, J. A. and A. Bueno Sánchez 1992. A new classification of the forests of the Muniellos Biological Reserve in Northwest Spain. Vegetatio 102:33-46.

Fernández Prieto, J. A., A. Bueno Sánchez, J. A. Alonso Felpete and B. Jiménez-Alfaro. 2002. Mapa de vegetación. Plan de Investigación de Muniellos 2002. INDUROT, Universidad de Oviedo, Principado de Asturias.

Gilbert, B. and M. J. Lechowicz. 2004. Neutrality, niches, and dispersal in a temperate forest understory. Proc. Natl. Acad. Sci. U. S. A. 101:7651-7656
Gilliam, F. S. 2007. The ecological significance of the herbaceous layer in temperate forest ecosystems. Bioscience 57:845-858.

Goslee, S. 2010. Correlation analysis of dissimilarity matrices. Plant Ecol. 206:279-286.

Guèze, M., J. Paneque-Gálvez, A. C. Luz, J. Pino, M. Orta-Martínez, V. Reyes-García and M. J. Macía. 2013. Determinants of tree species turnover in a southern Amazonian rain forest. J. Veg. Sci. 24:284-295.

Hubbell, S. P. 2001. The Unified Neutral Theory of Biodiversity and Biogeography. Princeton University Press, Princeton, New Jersey, USA.

Jiménez-Alfaro, B. and J.M. Iriondo, in press. Population dynamics of Aster pyrenaeus Desf., a threatened species of temperate forest edges: a view of meso- and micro-scales. Plant Biosystems. DOI 10.1080/11263504.2013.788094

Jones, M.M., H. Tuomisto, D.B. Clark and P. Olivas. 2006. Effects of mesoscale environmental heterogeneity and dispersal limitation on floristic variation in rain forest ferns. J. Ecol. 94: 181-195.

Jost, L. 2006. Entropy and diversity. Oikos 113:363-375.

Larsen, J. B. 1995. Ecological stability of forests and sustainable silviculture. For. Ecol. Manag. 73:85-96.

Lemmon, P. E. 1957. A new instrument for measuring forest overstory density. J. Forest. 55:667-668.

Li, Q., X. Yang, J. Soininen, C. J. Chu, J. Q. Zhang, K. L. Yu and G. Wang. 2011. Relative importance of spatial processes and environmental factors in shaping alpine meadow communities. $J$. Plant Ecol. 4:249-258.

Lichstein, J. W. 2007. Multiple regression on distance matrices: a multivariate spatial analysis tool. Plant Ecol. 188:117-131.

López Alvarez, J. 2002. La explotación del Monte de Muniellos (Asturias), 1766-1973. Ería: Revista cuatrimestral de geografia 58:273-286.

McCune, B. and D. Keon. 2002. Equations for potential annual direct incident radiation and heat load. J. Veg. Sci. 13:603-606.

Mikac, S., M. Klopf, I. Aniæ and H. Hasenauer. 2013. Using the tree growth model MOSES to assess the dynamics of Dinaric old-growth mixed beech-fir forest ecosystems. Plant Biosyst. 147:664-671.

Pausas, J. G. and M. P. Austin. 2001. Patterns of plant species richness in relation to different environments: An appraisal. J. Veg. Sci. 12:153-166.

Ricotta, C., S. Burrascano and C. Blasi. 2010. Incorporating functional dissimilarities into sample-based rarefaction curves: from taxon resampling to functional resampling. J. Veg. Sci. 21:280286.

Roekaerts, M. 2002. The Biogeographical Regions Map of EuropeBasic principles of its creation and overview of its development. European Environmental Agency, Copenhagen.

Royo, A. A. and W. P. Carson. 2006. On the formation of dense understory layers in forests worldwide: consequences and implications for forest dynamics, biodiversity, and succession. Can. J. For. Res. 36:1345-1362.

Sabatini, F. M., J. I. Burton, R. M. Scheller, K. L. Amatangelo and D. J. Mladenoff. 2014a. Functional diversity of ground-layer plant communities in old-growth and managed northern hardwood forests. Appl. Veg. Sci. 17:398-407.

Sabatini, F. M., S. Burrascano, H. Tuomisto and C. Blasi. 2014b. Ground Layer Plant Species Turnover and Beta Diversity in Southern-European Old-Growth Forests. PLoS ONE 9:e95244. 
Tobisch, T. and T. Standovár. 2005. A comparison of vegetation patterns in the tree and herb layers of a hardwood forest. Community Ecol. 6:29-37.

Travaglini, D., D. Paffetti, L. Bianchi, A. Bottacci, F. Bottalico, G. Giovannini, A. Maltoni, S. Nocentini, C. Vettori and G. Calamini. 2012. Characterization, structure and genetic dating of an old-growth beech-fir forest in the northern Apennines (Italy). Plant Biosyst. 146:175-188.

Tuomisto, H. 2010a. A diversity of beta diversities: straightening up a concept gone awry. Part 1 . Defining beta diversity as a function of alpha and gamma diversity. Ecography 33:2-22.

Tuomisto, H. 2010b. A diversity of beta diversities: straightening up a concept gone awry. Part 2. Quantifying beta diversity and related phenomena. Ecography 33:23-45.

Tuomisto, H. and K. Ruokolainen. 2006. Analyzing or explaining beta diversity? Understanding the targets of different methods of analysis. Ecology 87:2697-2708.

Tuomisto, H., K. Ruokolainen and M. Yli-Halla. 2003. Dispersal, environment, and floristic variation of western Amazonian forests. Science 299:241-244.

Višnjić, Ć., S. Solaković, F. Mekić, B. Balić, S. Vojniković, M Dautbašić, S. Gurda, F. Ioras, J. Ratnasingam and I. V. Abrudan. 2013. Comparison of structure, regeneration and dead wood in virgin forest remnant and managed forest on Grmeè Mountain in Western Bosnia. Plant Biosyst. 147:913-922.
Whittaker, R. H. 1960. Vegetation of the Siskiyou Mountains, Oregon and California. Ecol. Monogr. 30:407-407.

Yu, M. and O. J. Sun. 2013. Effects of forest patch type and site on herb-layer vegetation in a temperate forest ecosystem. For. Ecol. Manag. 300:14-20

Zhang, C. Y., X. H. Zhao and K. von Gadow. 2010. Partitioning temperate plant community structure at different scales. Acta Oecol. 36:306-313.

Received August 1, 2013

Revised November 28, December 9, 2013 Accepted December 12, 2013

\section{Supplementary material}

Appendix 1. Comparison tests of medians and variances between stands, Table S1.1.

Appendix 2. Correlation analysis, Table S2.1, Table S2.2.

Appendix 3. Graphs illustrating the individual effect of significant environmental variables on species richness, Fig. S3.1.

The file may be downloaded from www.akademiai.com 